\title{
Comparing Pre-Operative Fine Needle Aspiration Cytology to Paraffin Section Post-Operative for Solitary Thyroid Nodule
}

\author{
Mahmoud Reda Antar Elhammady, Mb Bch; ${ }^{1}$ Emad Eldin Farid Ebrahim, MD; ${ }^{2}$ Hoda Hassan \\ Abou Gabal, MD; ${ }^{3}$ Mohamed Mahmoud El-Matary, MD; ${ }^{4}$ Ehab Mohammed Ali Fadl, MD ${ }^{5}$ \\ ${ }^{1}$ General Surgery Resident, General Organization of Teaching Hospitals and Institutes, Egypt \\ ${ }^{2}$ Professor of General Surgery, Faculty of Medicine, Ain Shams University, Egypt \\ ${ }^{3}$ Associate Professor of Pathology, Faculty of Medicine, Ain Shams University, Egypt \\ ${ }^{4}$ Lecturer of General Surgery, Faculty of Medicine, Ain Shams University, Egypt \\ ${ }^{5}$ Lecturer of General Surgery, Faculty of Medicine, Ain Shams University, Egypt
}

Background: Fine needle aspiration cytology (FNAC) is considered the gold standard diagnostic test for the diagnosis of thyroid nodules. FNAC is a cost effective procedure that provides specific diagnosis rapidly with minimal complications. Based on the cytology findings, patients could be followed in cases of benign diagnosis and subjected to surgery in cases of malignant diagnosis therefore decreasing the rate of unnecessary surgery.

Aim of work: To correlate pre-operative fine needle aspiration cytology (FNAC) to post-operative paraffin section results in diagnosis of solitary thyroid nodule (STN).

Patients and methods: This is a prospective study, it was performed on 30 patients diagnosed as solitary thyroid nodule; the results for FNAC and histopathological examination were reviewed, evaluated and correlated.

Results: On FNAC, out of 30 cases there were 19 benign lesions; 17 (56.66\%) cases were true negative (TN) and $2(6.67 \%)$ cases were false negative (FN).

There were $11(36.67 \%)$ of undetermined significance or suspicious neoplastic lesions diagnosed by FNAC; 10 (33.33\%) cases were true positive (TP) and only one (3.33\%) case was false positive (FP). After comparison of results of FNAC with histopathology, the sensitivity, specificity, accuracy, positive predictive value and negative predictive value were $83.33 \%, 94.44 \%, 90 \%, 90.91 \%$ and $89.47 \%$, respectively.

Conclusion: Fine needle aspiration was a significantly better predictor of malignancy, we recommend this procedure in the light of other investigations as a primary investigation of thyroid lesions in a patient with solitary thyroid nodules as it should be advised for exclusion of malignancy.

Key words: Fine needle aspiration cytology, solitary thyroid nodule, paraffin section.

\section{Introduction}

Solitary thyroid nodule (STN) is a single swelling in the thyroid tissue that is radiologically remarkable from the rest of thyroid parenchyma. ${ }^{1}$ STN is found either by self-examination by the patient, during a clinical assessment by the clinician or incidentally discovered on radiological procedures. ${ }^{2}$

Thyroid nodules are common; they are more frequent in females than males and their prevalence increases with age and body mass index. ${ }^{3}$ Clinically palpable nodules are experienced in about $8 \%$ of the adult population, with the use of imaging procedures specially ultrasound; the possibility of recognition of thyroid nodules has significantly increased. ${ }^{4}$

The prevalence of thyroid malignancy is low; being just about $1 \%$. However, it was reported that the rate of thyroid cancer is expanding over the years.
Thyroid malignancy occurs in about $5 \%$ of all thyroid nodules irrelevant of their size.5,6 The possibility of malignancy is more in cases with STN compared to those with multi-nodular goiter. ${ }^{7,8}$

Thyroid nodules are of a specific concern when they are found in cases less than 20 years old as it is has more risk of malignancy in such young age group. ${ }^{9}$

The pre-operative assessment of thyroid nodules is crucial to differentiate between benign and malignant nodules. It also assists to avoid unnecessary surgical procedures and subsequent possible complications such as hypothyroidism, parathyroid or laryngeal nerves injury. ${ }^{4}$ FNAC is the gold standard technique in the assessment of thyroid nodules; it is described as quick, reliable, cost effective and minimally invasive. One of the significant points of interest is that FNAC could be done as an out-patient procedure. According to many studies it has led to significant decrease in surgical procedures of the 
patients with thyroid nodules; however it shares to an increase in percentage of thyroid surgeries with malignant lesions. ${ }^{10}$

FNAC, especially ultrasound guided is very safe diagnostic procedure in the management of thyroid nodules. Post FNAC local pain and minor hematoma are the most common complications, while serious complications seem to be rare. ${ }^{11}$

The success of FNAC depends on several factors such as aspirator experience, skillful cytological interpretation and rational analysis of cytological and clinical data. Still the histopathological examination of the thyroid gland is considered as superior to FNAC in diagnosing the thyroid pathologies due to certain pitfalls in FNAC such as scanty sample, vascularity of thyroid swelling variation in sampling technique and inability to differentiate between follicular adenoma from follicular carcinoma, beside the possibility of false negative and false positive. ${ }^{12,13}$

\section{Aim of the work}

To correlate the fine needle aspiration cytology findings with the histopathology of excised specimens.

\section{Patients and methods}

This is a prospective study that performed on 30 patients with the clinical diagnosis of STN, all patients were selected from those attending the outpatient clinics of general surgery department at Ain Shams University and National Institute of Diabetes and Endocrinology from April 2020 to March 2021. All patients had been subjected to both FNAC and surgical intervention during this period.

Inclusion criteria: All patients with STN, irrespective of the age who underwent FNAC of the swelling, followed by its subsequent post-operative histopathological examination were included in the study.

Exclusion criteria: All patients with diffuse goiter, toxic or multiple thyroid nodules.

Ethical considerations: Detailed explanation of the procedure to the patient. Written consent was obtained from the patients according to ethical committee considerations. All patients signed a consent reviewing the tests, medications and procedures including all complications and test results.

Study tools: The patients with thyroid swellings were evaluated in following order; History, Physical examination, Investigations (Diagnostic imaging and FNAC) and histopathological evaluation of resected specimen. Eventually, statistical evaluation and correlation of FNAC to histopathological examination.
Study procedures: ultrasound-guided fine needle aspiration biopsy (FNAB) was done by radiologist using 23 gauge needle and $5 \mathrm{ml}$ syringe under aseptic precautions. Smears were fixed with ether-95\% alcohol solution, and staining was performed. The stained slides were seen under light microscope. After FNAC, all the patients were subjected to surgery; hemi-thyroidectomy for benign smears, total thyroidectomy for suspicious or malignant cases and total thyroidectomy with selective neck dissection for malignant cases with positive lymph nodes after pre-operative preparation and anesthesia checkup. Finally, data was collected, tabulated and statistically analyzed.

\section{Results}

\section{Demographic data of the patients}

This study included 30 patients with symptomatic solitary thyroid nodule, including 25 (83.33\%) female patients and $5(16.67 \%)$ male patients. Overall, $5(16.67 \%)$ patients were aged less than 30 years, $12(40 \%)$ patients were aged 30 to less than 40 years, $7(23.33 \%)$ patients were aged 40 to 50 years, and $6(20 \%)$ patients were older than 50 years, with mean age of $(39.45 \pm 11.76)$ years (Table 1).

\section{Findings on neck ultrasonography of the studied patients:}

All patients had solitary thyroid nodule; 17 (56.67\%) patients had right-side nodule while 12 (40\%) patients had left-side nodule and 1 (3.33\%) patient had an isthmic nodule. Size of the nodule (according to ultrasound measurement) was variable, $8(26.67 \%)$ patients had size of the nodule [ $<2$ centimeter $(\mathrm{cm})], 11(36.67 \%)$ patients had size of the nodule $[2-3 \mathrm{~cm}]$, and $11(36.67 \%)$ patients had size of the nodule $[>3 \mathrm{~cm}]$. There were $3(10 \%)$ patients had retrosternal extension (Table 2 ).

Table 3 shows final histopathological examination (HPE) in different categories of US findings as per Thyroid Imaging Reporting And Data System (TIRADS). The malignancy risk increased with the TIRADS categories 3 to 5 . The incidence of malignancy in STN was more in females. There were 7 malignant lesions all of them were females .Preoperative investigation of TIRADS score demonstrated that the risk of malignancy were $0 \%, 18.75 \%$ and $66.76 \%$ for TIRADS3, 4 and 5 respectively.

\section{Findings of fine needle aspiration cytology in the current study}

Out of 30 patients included in the study, FNAC was done in all patients (100\%). Colloid nodule [Bethesda (B) II] $13(43.33 \%)$ patients while Hyperplastic nodule [B II] 4 (13.33\%) patients, lymphocytic Thyroiditis [B II] 2 (6.67\%) patients, follicular neoplasm [B III] 
$4(13.33 \%)$ patients, Hurthle cell tumor [B IV] 2 (6.67\%)patients, suspected for malignancy [B V] $3(10 \%)$ patients and papillary carcinoma [B VI] 2 (6.67\%) patients (Table 4).

\section{Type of thyroidectomy in the current study}

Total thyroidectomy was performed in 7 (23.33\%) patients; Hemi-thyroidectomy was performed in 23 (76.76\%) patients; right-side hemi-thyroidectomy in $12(40 \%)$ patients and left-side hemi-thyroidectomy in $11(36.67 \%)$ patients (Table 5).

\section{Histopathological findings in the study}

The most frequent findings in the HPE in the current study was colloid nodule occurred in 13 (43.33\%). Hyperplastic nodule was found in $3(10 \%)$ cases. Hashimoto's Thyroiditis in 2 (6.67\%) patients, Hurthle cell adenoma only in 1 (3.33\%) patient, Hurthle cell carcinoma in 1 (3.33\%) patient and papillary carcinoma presented in $6(20 \%)$ patients (Table 6).

\section{Postoperative status and complications in the current study:}

Complications postoperatively were hoarseness of voice in $2(6.66 \%)$ patients; one $(3.3 \%)$ of them was due to unilateral recurrent laryngeal nerve injury and the other one (3.33\%) was due to laryngeal edema (both of them underwent vocal cord examination), and transient hypocalcaemia (in the form of numbness at circum-oral area, hands and feet) occurred only in 1 (3.3\%) patient (Table 7).

\section{Completion thyroidectomy post hemithyroidectomy}

Completion thyroidectomy was done in 1 (3.33\%) case in our study in which FNAC result was hyperplastic nodule, therefor hemithyroidectomy was done but HPE result was papillary carcinoma.
Therefore, the case underwent completion thyroidectomy of the other lobe within 2 weeks (Table 8).

\section{Correlation between cytological and histopathological analysis results}

There was $1(3.33 \%)$ case with a result of false positive (FP) diagnosis; diagnosed as follicular neoplasm by FNAC examination and the HPE was Hyperplastic nodule. There were 2 (6.67\%) cases with results of false negative (FN) had been reported as Hyperplastic nodule by FNAC examination and their HPE were follicular adenoma and papillary carcinoma as summarized in (Table 9).

There were 19 (63.33\%) benign lesions; 2 (6.67\%) FN cases (Summarized in (Table 9) and 17 (56.67\%) cases were true negative (TN); 13 (43.33\%) cases were colloid nodule, $2(6.67 \%)$ cases were lymphocytic thyroiditis and $2(6.67 \%)$ cases were Hyperplastic nodule by FNAC examination confirmed by histopathological examination.

There were 11 (36.67\%) undetermined significance or suspicious neoplastic lesions diagnosed by FNAC; $10(33.33 \%)$ cases were true positive (TP) and 1 (3.33\%) case was FP. The TP cases were; 3 (10\%) follicular neoplasm, 3 (10\%) suspected malignancy and $2(6.67 \%)$ papillary carcinoma by FNAC that confirmed by HPE. The other $2(6.66 \%)$ cases were Hurthle cell tumor by FNAC and HPE reported; 1 (3.33\%) Hurthle cell adenoma and 1 (3.33\%) Hurthle cell carcinoma. The FP case was follicular neoplasm by FNAC examination and HPE was Hyperplastic nodule (Table 11).

After comparison of results of FNAC with HPE, the sensitivity, specificity, accuracy, positive predictive value and negative predictive value were $83.33 \%$, $94.44 \%, 90 \%, 90.91 \%$ and $89.47 \%$, respectively (Table 12).

Table 1: Age and sex distribution of the studied patients

\begin{tabular}{ll}
\hline Charactaristics & $\mathbf{n}(\mathbf{\%})($ Total $\mathbf{n = 3 0})$ \\
\hline Age & \\
$<30$ & $5(16.67 \%)$ \\
$30-39$ & $12(40 \%)$ \\
$40-50$ & $7(23.33 \%)$ \\
$>50$ & $6(20 \%)$ \\
Mean \pm SD & $39.45 \pm 11.76$ \\
Range & $18-63$ \\
Sex & \\
Male & $5(16.67 \%)$ \\
Female & $25(83.33 \%)$ \\
\hline
\end{tabular}


Table 2: Findings on neck ultrasonography of the studied patients

\begin{tabular}{ll}
\hline US finding & $\mathbf{n}(\mathbf{\%}) \mathbf{( T o t a l} \mathbf{n = 3 0 )}$ \\
\hline Single nodule & $30(100 \%)$ \\
Right lobe & $17(56.67 \%)$ \\
Left lobe & $12(40 \%)$ \\
Isthmus & $1(3.33 \%)$ \\
Size of nodule $(\mathbf{c m})$ & \\
$<2$ & $8(26.67 \%)$ \\
$2-3$ & $11(36.67 \%)$ \\
$>3$ & $11(36.67 \%)$ \\
Presence of retrosternal extension & $3(10 \%)$ \\
\hline
\end{tabular}

Table 3: Proportion of malignancy as per TIRADS Score

\begin{tabular}{ccccc}
\hline \multirow{2}{*}{ TIRADS Score } & \multicolumn{2}{c}{ Histopathology } & \multirow{2}{*}{ Total } & Risk of malignancy\% \\
\cline { 2 - 3 } & Benign & Malignant & & $0 \%$ \\
\hline 3 & 8 & 0 & 8 & $18.75 \%$ \\
5 & 13 & 3 & 6 & $66.67 \%$ \\
\hline
\end{tabular}

Table 4: Preoperative findings of fine-needle aspiration cytology in the current study

\begin{tabular}{lc}
\hline Preoperative FNAC & n (\%) (Total $\mathbf{~ = 3 0 ) ~}$ \\
\hline Colloid nodule (Bethesda II) & $13(43.33 \%)$ \\
Hyperplastic nodule (Bethesda II) & $4(13.33 \%)$ \\
Lymphocytic thyroiditis (Bethesda II) & $2(6.67 \%)$ \\
Follicular neoplasm (Bethesda III) & $4(13.33 \%)$ \\
Hurthle cell tumor (Bethesda IV) & $2(6.67 \%)$ \\
Suspected malignancy (Bethesda V) & $3(10 \%)$ \\
Papillary carcinoma (Bethesda VI) & $2(6.67 \%)$ \\
\hline
\end{tabular}

Table 5: Type of operations performed in this study

\begin{tabular}{lc}
\hline Type of operation & $\mathbf{n ~ ( \% ) ~ ( T o t a l ~} \mathbf{n = 3 0 )}$ \\
\hline Right Hemithyroidectomy & $12(36.67 \%)$ \\
Left Hemithyroidectomy & $11(36.67 \%)$ \\
Total thyroidectomy & $7(23.33 \%)$ \\
\hline
\end{tabular}

Table 6: Postoperative histopathology findings in the current study

\begin{tabular}{lc}
\hline Histopathological report & $\mathbf{n}(\mathbf{\%}) \mathbf{( T o t a l ~} \mathbf{n = 3 0 )}$ \\
\hline Colloid nodule & $13(43.33 \%)$ \\
Hyperplastic nodule & $3(10 \%)$ \\
Hashimoto's Thyroiditis & $2(6.67 \%)$ \\
Follicular adenoma & $4(13.33 \%)$ \\
Hurthle cell adenoma & $1(3.33 \%)$ \\
Hurthle cell carcinoma & $1(3.33 \%)$ \\
Papillary carcinoma & $6(20 \%)$ \\
\hline
\end{tabular}


Table 7: Postoperative status and complications in the current study

\begin{tabular}{lc}
\hline Complications & $\mathbf{n}(\mathbf{\%}) \mathbf{( T o t a l} \mathbf{n = 3 0 )}$ \\
\hline Unilateral RLN injury & $1(3.33 \%)$ \\
Laryngeal edema & $1(3.33 \%)$ \\
Transient hypocalcemia & $1(3.33 \%)$ \\
No complications & $27(90 \%)$ \\
\hline
\end{tabular}

Table 8: Completion thyroidectomy post hemithyroidectomy

\begin{tabular}{lc}
\hline Completion Hemithyroidectomy & $\mathbf{n}(\mathbf{\%})($ Total $\mathbf{n = 3 0})$ \\
\hline Yes & $1(3.33 \%)$ \\
No & $29(96.66 \%)$ \\
\hline
\end{tabular}

Table 9: Summary of false positive and false negative results of FNAC

\begin{tabular}{ll}
\hline FNAC finding & Histopathology report \\
\hline False positive (1 case) & Hyperplastic nodule \\
Follicular neoplasm & \\
False negative ( 2 cases) & Follicular adenoma \\
Hyperplastic nodule & Papillary carcinoma \\
Hyperplastic nodule &
\end{tabular}

Table 10: Non-neoplastic lesions diagnosed by FNAC and their comparison with histopathological diagnosis

\begin{tabular}{lccc}
\hline FNAC Report & $\begin{array}{c}\text { Number of } \\
\text { patients }=\mathbf{1 9}\end{array}$ & Histopathological reports & Remarks \\
\hline Colloid nodule & $13(43.33 \%)$ & Colloid nodule & True negative \\
Hashimoto's Thyroiditis & $2(6.67 \%)$ & Hashimoto & True negative \\
Hyperplastic nodule & $2(6.67 \%)$ & Hyperplastic nodule & True negative \\
Hyperplastic nodule & $1(3.33 \%)$ & Follicular adenoma & False negative \\
Hyperplastic nodule & $1(3.33 \%)$ & Papillary carcinoma & False negative \\
\hline
\end{tabular}

Table 11: Undetermined significance or suspicious neoplastic lesions diagnosed by FNAC and their comparison with histopathological diagnosis

\begin{tabular}{|c|c|c|c|c|}
\hline FNAC Report & $\begin{array}{c}\text { Number of } \\
\text { patients }= \\
11\end{array}$ & Histopathological reports & $\begin{array}{c}\text { Number of } \\
\text { patients= } \\
11\end{array}$ & Remarks \\
\hline Hurthle cell tumor & $2(6.67 \%)$ & $\begin{array}{l}\text { Hurthle cell adenoma } \\
\text { Hurthle cell carcinoma }\end{array}$ & $\begin{array}{l}1(3.33 \%) \\
1(3.33 \%)\end{array}$ & $\begin{array}{l}\text { True positive } \\
\text { True positive }\end{array}$ \\
\hline Follicular neoplasm & $4(13.33 \%)$ & $\begin{array}{l}\text { Follicular adenoma } \\
\text { Hyperplastic nodule }\end{array}$ & $\begin{array}{r}3(10 \%) \\
1(3.33 \%)\end{array}$ & $\begin{array}{l}\text { True positive } \\
\text { False positive }\end{array}$ \\
\hline Suspected malignancy & $3(10 \%)$ & Papillary carcinoma & $3(10 \%)$ & True positive \\
\hline Papillary carcinoma & $2(6.67 \%)$ & Papillary carcinoma & $2(6.67 \%)$ & True positive \\
\hline
\end{tabular}

Table 12: Overall performance of fine-needle aspiration cytology in diagnosis of thyroid neoplasm

\begin{tabular}{lc}
\hline Sensitivity & $83.33 \%$ \\
Specificity & $94.44 \%$ \\
Accuracy & $90 \%$ \\
Positive predictive value & $90.91 \%$ \\
Negative predictive value & $89.47 \%$ \\
\hline
\end{tabular}




\section{Discussion}

\section{Demographic data of the patients}

In this study total number of patients were 30 , all of them were clinically and biochemically euthyroid and investigated by pre-operative FNAC and postoperative histopathological examination. Patients in this study belonged to the age group of 18 to 63 years with mean age \pm SD $39.45 \pm 11.76$ years; the age range and mean are close to studies by Gupta et al., in $2010^{7}$ and Mitra et al., in $2002^{14}$ in which age range were 22 to 58,16 to 70 and mean age were 39.6, 38.7 years respectively. Ibrahim et al in $2019^{15}$ has reported that most patients were females and mean age \pm SD was $36.96 \pm 11.1$ years which corroborates with our findings.

In our study, the highest age incidence was found to be in the fourth decade of life ( $40 \%$ of patients) and much less below 20 and above 60 years old. This is similar with the other studies by Ibrahim et al in 2019, ${ }^{15}$ Huque et al., in $2102^{16}$ and Harshvardhan et al., in 2020.17

In our study, all patients had STN, the female: Male ratio was $5: 1$, these results are in agreement with other studies that were on patients with STN by Basharat et al., in $2011^{18}$ who found a female: Male ratio of $4.6: 1$ and a study by Lakshmi et al., in $2020^{19}$ who reported that female: Male ratio was 4:1. Other studies reported more female predominance in a ratio 11.5 : 1 by Haider et al., in $2021^{20}$ and another study by Harshvardhan et al., in $2020^{17}$ reported female: Male ratio 7.5:1.

\section{Clinical presentation}

STN is a palpable nodule in otherwise apparently normal thyroid gland. ${ }^{21}$ The clinical spectrum ranges from the incidental, asymptomatic, small, solitary nodule in which the exclusion of cancer is the major concern, to the large, partly intra-thoracic nodule that causes pressure symptoms, for which treatment is warranted regardless of cause. History and Physical examination remains the cornerstone in the evaluation of solitary thyroid nodule. ${ }^{22}$

In this study, Swelling anterior to the neck was the most frequent symptom. 29 (96.66\%) out of 30 patients were presented with a swelling at the front of the neck and $1(3.33 \%)$ patient presented with neck pain besides the swelling. In another study by Haider et al., in 2021,20 Thyroid swelling was present in all patients, besides thyroid swellings, $8 \%$ of the patients had pain and $4 \%$ had irritation in their throats. On the other hand, Hassan et al., in $2013^{23}$ reported that there was pain in the nodule in $4 \%$ and dysphagia (6\%). Bhamre et al., in $2019^{22}$ also mentioned that the most common presenting feature was swelling (100\% of cases) followed by pain in $14.3 \%$, dysphagia was seen in $5.7 \%$ cases.
Sharma et al., in $2017^{24}$ also reported that the common presenting complaint (99.5\% of cases) was swelling in thyroid region and associated pain was present in few cases.

Presence of pressure symptoms is uncommon with solitary thyroid nodule as nodules are usually not large enough. However, presence of pressure symptoms is a poor prognostic factor as it is commonly associated with malignancy. Pressure symptoms arise because of pressure on trachea, esophagus, recurrent laryngeal nerve manifesting as stridor, dysphagia or hoarseness of voice respectively. ${ }^{22}$

In the current study there is no cases presented with pressure symptoms, but other studies of STN by Tarrar et al., in $2010^{25}$ observed incidence of patients presenting with pressure symptoms was $5 \%$ and a study by Keshri et al., in $2017^{26}$ reported a pressure manifestation in the form of dyspnea and dysphagia was seen in $4 \%$ and $15 \%$ cases respectively. Another study by Bhamre et al., in $2019^{22}$ reported $5.7 \%$ of cases had a pressure manifestation in the form of dysphagia.

\section{Examination}

In the literature, it is clearly indicated that the nodule size is a weak predictor of histological malignancy. ${ }^{27}$ In our study; 8 patients (26.67\%) had less than 2 $\mathrm{cm}$ sized thyroid nodule, 11 patients $(36.67 \%)$ had 2 to $3 \mathrm{~cm}$ thyroid nodule and 11 patients (36.67\%) had more than $3 \mathrm{~cm}$ thyroid nodule. The rate of malignancy was almost the same in our data, and the chances of malignancy were independent of its size. Our findings are consistent with a study by Mihailescu and Schneider, 2008. ${ }^{28}$

In the current study, all patients had solitary thyroid nodule; $17(56.67 \%)$ patients had right-side nodule while $12(40 \%)$ patients had left-side nodule and 1 (3.33\%) patients had an isthmic nodule.

A similar study by Haider et al., in $2021^{20}$ which is very close to our results; 50 patients were included in the study, $28(56 \%)$ of patients had a solitary nodule at the right lobe while $19(38 \%)$ of patients had a left side lobe nodule and $3(6 \%)$ had an isthmic nodule.

Another study by Nasr et., al in $2020^{29}$ that 135 patients were included, all the patient had solitary thyroid nodule, $94(70 \%)$ patients had right-side nodule while 41 (30\%) patients had left-side nodule.

A study by Jaykar et al., in $2021^{30}$ which 30 patients were included, $19(66.67 \%)$ patients had a Right side STN while 11 (33.33\%) had left side nodule.

In our study the size of the nodule was less than $2 \mathrm{Cm}$ in $8(26.67 \%)$ patients, from 2 to $3 \mathrm{~cm}$ in $11(33.33 \%)$ patients and more than $3 \mathrm{~cm}$ in 11 
(33.33\%) patients. A study by Nasr et., al in $2020^{29}$ revealed that the size of thyroid nodules is not reliable at predicting malignancy and should not be applied in medical decision making, this is in agree with studies by Cavallo et al., in $2017^{31}$ and Godazandeh et al., in 2016. ${ }^{32}$

Another study by Valderrabano et al., in $2018^{33}$ indicated that regardless of size, comparing tumors of less than $4 \mathrm{~cm}$ with those $4 \mathrm{~cm}$ or greater, size was not seen as a categorical or continuous variable in relation to cancer rate. Moreover, the prevalence of extra-thyroidal extension, positive margins, lympho-vascular invasion, lymph node metastasis, and distant metastasis did not differ by size. The investigators also found the majority of malignant tumors in both size groups to below- risk lesions.

Thyroid imaging reporting and data system (TIRADS) is the assessment of a risk stratification of thyroid nodules, usually using a score. A study by Kwak et al., in $2011^{34}$ have proposed a TIRADS score by retrospective analysis of thyroid nodules in ultrasound and FNAC, using five ultrasound criteria that can be used during thyroid evaluation, this article described that a malignancy risk of $0 \%$ is expected for TIRADS 2, $1.7 \%$ for TIRADS 3, a risk of $72.4 \%$ for TIRADS 4 , and of $87.5 \%$ for TIRADS 5 .

In our study, the risk of malignancy for TIRADS 3,4 and 5 were $0.0 \%, 18.75 \%$ and $86.66 \%$, respectively. According to another Indian study by Srinivas et al., in $2016^{35}$ it was concluded that the risk of malignancy for TIRADS categories $1,2,3,4 \mathrm{~A}$, $4 \mathrm{~B}, 4 \mathrm{C}$, and 5 was $0,0,0.64,4.76,66.67,83.33$, and $100 \%$, respectively.

Our results are within the range suggested by De, et al., in $2020^{36}$ which reported a risk of malignancy for TIRADS 3,4 and 5 were $22.72 \%, 29.16 \%$ and $86.66 \%$ respectively.

\section{Fine Needle Aspiration Cytology}

In our study, preoperative FNAC was done for all patient (100\%) patients. Colloid nodule $13(43.33 \%)$ patients while hyperplastic nodule $4(13.33 \%)$, lymphocytic infiltration 2 (6.66\%) patients, follicular neoplasm $4(13.33 \%)$ patients, Hurthle cell tumor $2(6.66 \%)$ and papillary carcinoma or suspected for malignancy 5 (16.67\%) patients.

In a study by Bhamre et al., in 2019, 22 as per FNAC report, colloid goiter was the most common observation (51.4\%) followed by adenomatous goiter (17.1\%). Papillary and medullary carcinoma was seen in $14.3 \%$ and $2.9 \%$ respectively. Suspicious FNAC report was given in 2 cases (5.7\%). Keshri et al., in $2017^{26}$ on FNAC observed that $58 \%$ of nodules were benign and $12 \%$ were malignant, out of the total 58 benign samples, 25 (43\%) of benign lesion were colloid nodule. Another study by Kaur et al., in $2002^{37}$ observed following FNAC findings: Benign (64\%), suspicious (20\%), malignant (10\%) and indeterminate (6\%).

A study by Sachin ID et al., in $2019^{38}$ reported that the benign category occupies the major group with $61 \%$ of cases, followed by suspicious were $29 \%$ of cases and malignant were $10 \%$ of cases. There is no inadequate or insufficient cytological smear while a study by Rajendran et al., in $2018^{39}$ observed majority of FNAC reported colloid goiter $(84 \%), 14 \%$ showed papillary carcinoma followed by follicular neoplasm (2\%).

\section{Complications}

In our study there were $2(6.67 \%)$ patients who had a voice change; 1 (3.33\%) case was due to laryngeal edema and had an improvement to conservative treatment with complete recovery within 3 weeks post-operative, while the other case (3.33\%) was due to unilateral recurrent laryngeal nerve injury post total thyroidectomy procedure, both of them diagnosed by clinical assessment and vocal cord examination. Another 1 (3.33\%) female patient that had transient hypocalcemia in a form of numbness at circum-oral area, hands and feet. She had an improvement after calcium and vitamin D supplements.

A study by Jaykar et al., in 2021,30 reported out of 30 cases, 1 (3.33\%) patient who underwent Total thyroidectomy developed hypocalcemia that was treated conservatively and the patient recovered during post-operative period, 1 (3.33\%) patient was diagnosed as having unilateral vocal cord paresis, after he had persistent hoarseness of voice even on the 5th post-operative day. Patient was treated conservatively and he recovered by 30th postoperative day.

2 (6.66\%) Patients with wound dehiscence responded to conservative management with antibiotics.

Another study by Nasr et al, in $2020,{ }^{29}$ reported postoperative complications out of 132 patients there were $9(6.82 \%)$ cases with temporary hypocalcaemia and $3(2.27 \%)$ patients with hoarseness of voice due to laryngeal edema.

\section{Histopathology}

In the current study, the histopathological examination was colloid goiter for 13 (43.33\%) of patients, it was the most common observation in cases of solitary thyroid nodule. Hyperplastic nodule was noted in $3(10 \%)$ patients. Hashimoto's thyroiditis was observed in $2(6.67 \%)$ patients.

Other findings included follicular adenoma which was noted in $4(13.33 \%)$ patients. Hurthle cell adenoma was in 1 (3.33\%) patient and Hurthle 
cell carcinoma was in 1 (3.33\%) patient as well. papillary carcinoma was in $6(20 \%)$ patients. Out of total 30 cases, $76.67 \%$ were benign pathologies while $23.33 \%$ were malignant pathologies. Most common benign lesion was colloid goiter (43.33\%) while most common malignant lesion was papillary carcinoma (20\%).

A study by Bhamre S et al., in 2019, ${ }^{22}$ reported, colloid goiter (31.4\%) was the most common observation in cases of solitary thyroid nodule followed by nodular hyperplasia (20\%) and adenomatous goiter (17.1\%). adenoma (8.6\%), papillary carcinoma (14.3\%), follicular variant of papillary carcinoma (5.7\%) and medullary carcinoma (2.9\%). $77.1 \%$ were benign pathologies while $22.9 \%$ were malignant pathologies. Most common benign lesion was colloid goiter (31.4\%) followed by multinodular goiter (20\%) while most common malignant lesion was papillary carcinoma (14.3\%) followed by medullary carcinoma (2.9\%).

In a study by Keshri et al., in $2017^{26} 79 \%$ of clinically diagnosed solitary nodules were benign and $21 \%$ of nodule were malignant. Most common benign nodule was benign follicular adenoma (31\%) followed by colloid nodule (24\%) while prevalence of multinodular goiter was $17 \%$. Most common malignant lesion was papillary carcinoma (13\%) followed by medullary carcinoma (3\%).

In another similar study by Muddegowda et al., in $2012,{ }^{40}$ out of 162 cases, 138 (85.18\%) were diagnosed as non-neoplastic lesions, while the rest $24(24.82 \%)$ were diagnosed as a neoplastic lesions. Among the 138 non-neoplastic lesions, the commonest lesion was colloid goiter seen in 56 cases while papillary carcinoma was the commonest malignant lesion.

\section{Comparison of FNAC with histopathology}

The false positive rate (FPR) indicates that a patient with malignant FNAC result was found on histological examination to have benign lesion. In this study there was only $1(3.33 \%)$ case with a result of FP diagnosis; diagnosed as follicular neoplasm by FNAC examination and HPE was hyperplastic nodule. There were $2(6.67 \%)$ cases with a result of FN had been reported as hyperplastic nodule by FNAC examination and their HPE were follicular adenoma and papillary carcinoma.

In a similar study by Basharat et al. in $2011,{ }^{18}$ out of 50 patients reported 1 (2\%) case with a FP result, diagnosed as malignant on FNAC but it turned out to be diffuse hyperplasia on histopathology and $1(2 \%)$ case as FN result diagnosed as benign by FNAC but histopathological examination was follicular carcinoma.

Another study by Susmitha eta al. 2017.41 Statistics showed out of 40 patients there were 7 (17.5\%) of them false negatives; 2 (5\%) papillary carcinoma cases were misdiagnosed as non-neoplastic on cytology and 5 (12.5\%) benign neoplasm by HPE misdiagnosed as a non-neoplastic by FNAC and $3(7.5 \%)$ patients were FP; 2 (5\%) of them were false positives for neoplasms ( FNAC was follicular neoplasm but HPE were colloid goiter), 1 (2.5\%) false positive for malignancy (follicular adenoma was misdiagnosed as medullary carcinoma on FNAC). On the other hand a study by Dantanarayana et al. in $2019,{ }^{42}$ reported a false positive rate in a percentage $8.6 \%$ and a high false negative rate with a percentage of $39.3 \%$ of total cases.

A study by Iqbal et al., in $2016 .{ }^{43}$ that included 321 patients, the number of true positive were 109 (33.96\%) of total cases; 16 (5\%) cases were papillary carcinoma, $35(10.91 \%)$ cases were follicular neoplasm and 59 (18.38\%) patients were atypical cells. The true negative cases were 212 (66.04\%); all of them were diagnosed as colloid nodular goiter.

\section{Overall performance of fine-needle aspiration}

In our study, after comparison between FNAC and HPE, the sensitivity, specificity, accuracy, positive predictive value and negative predictive value were (83.33\%), (94.44\%), (90\%), (90.91\%) and (89.47\%) respectively.

Our results are close to a study by Haider et al in $2021,{ }^{20}$ Sensitivity was $83.3 \%$, Specificity $86.8 \%$, Accuracy $86 \%$, positive predictive value $66.6 \%$ and negative predictive value $94.28 \%$. Another similar study by Harshvardhan et al., in 2020,17 reported sensitivity and specificity of FNAC were $81.25 \%$ $\$ 98.84 \%$ respectively.

A study by Karim et al., in $2019 .{ }^{44}$ that 160 patients were included, Sensitivity was $90.2 \%$, Specificity $98.2 \%$, Accuracy $97.1 \%$, while a study by Bamanikar et al., in 2014, ${ }^{45}$ that 300 patients were included, Sensitivity was 65\%, Specificity $98 \%$ and Accuracy $94.2 \%$.

A study by Dantanarayana et al., in 2019. ${ }^{37}$ that 63 patients were included, sensitivity (60.7\%), specificity (91.4\%), positive predictive value (85\%), and negative predictive value (74.4\%).

Another study by Bukhari eta al., in $2008,{ }^{46}$ that 76 patients were included, overall sensitivity of FNAC was found to be $78.5 \%$, specificity as $(96.8 \%)$, and accuracy as $93.4 \%$, while positive predictive value was $84.6 \%$ and negative predictive value was $95 \%$.

\section{Conclusion}

In the conclusion of this study the FNAC observed to be with high efficacy in detecting thyroid malignancies in solitary thyroid nodules. It is simple, 
safe, reliable, and remains a powerful diagnostic tool for thyroid lesions. It allows clinicians to reach an effective diagnosis in large number of cases with less time and expense and to prevent needless surgery in many cases. It is secure, simple to use, precise, and low-cost, however benign lesions by FNAC diagnosis with high risk features on ultrasound (US) should be viewed with caution as false negative results do occur and these subjects should be followed. The pathologist and clinician would work closely together, that will provide useful information in the majority of cases to approach a precise diagnosis.

\section{References}

1. Haugen BR, Alexander EK, Bible $\mathrm{KC}$, et al: American Thyroid Association Management Guidelines for Adult Patients with Thyroid Nodules and Differentiated Thyroid Cancer: The American Thyroid Association Guidelines. Task Force on Thyroid Nodules and Differentiated Thyroid Cancer. Thyroid 2016; 26(1): 1-133.

2. Davies L, Welch HG: Current thyroid cancer trends in the United States. JAMA Otolaryngol Head Neck Surg 2014; 140(4): 317-322.

3. Fisher $\mathrm{SB}$, Perrier ND: The incidental thyroid nodule. CA Cancer J Clin. 2018; 68(2): 97-105.

4. Tai JD, Yang JL, Wu SC, Wang BW, Chang CJ: Risk factors for malignancy in patients with solitary thyroid nodules and their impact on the management. J Cancer Res Ther. 2012; 8: 379383.

5. Yeung MJ, Serpell JW: Management of the solitary thyroid nodule. Oncologist. 2008; 13(1): 105112.

6. Unnikrishnan AG, Kalra $S$, Baruah $M$, et al: Endocrine Society of India management guidelines for patients with thyroid nodules: A position statement. Indian J Endocrinol Metab. 2011; 15(1): 28.

7. Gupta M, Gupta S, Gupta VB: Correlation of fine needle aspiration cytology with histopathology in the diagnosis of solitary thyroid nodule. J Thyroid Res. 2010. Article: 379051.

8. Iqbal M, Mehmood Z, Rasul S, et al: Carcinoma thyroid in multi and uninodular goiter. $\boldsymbol{J}$ Coll Physicians Surg Pak. 2010; 20(5): 310-312.

9. Carling T, Udelsman R: Thyroid cancer. Annu Rev Med. 2014; 65(3): 125-137.

10. Yassa L, Cibas ES, Benson CB: Long- term assessment of a multidisciplinary approach to thyroid nodule diagnostic evaluation. Cancer. 2007; 111(6): 508-516.

11. PolyzosSA, AnastasilakisAD: Clinical complications following thyroid fine-needle biopsy: a systematic review. Clinical Endocrinology. 2009; 71(2): 157165.

12. Roy PK, Bandyopadhyay S, Dubey $A B$, et al. Comparative Study on Aspiration Cytology and Histopathology in Diagnosis of Thyroid Nodule and Its Correlation. Indian Journal of Otolaryngology and Head and Neck Surgery. 2019; 71(1): 997-1001.

13. Shere SK, Kulkarni AS, Phulgirkar PP, et al: Correlation of fine needle aspiration cytology with histopathology in diagnosis of thyroid lesions. Journal of Evolution of Medical and Dental Sciences. 2013; 2(26): 4826-4831.

14. Mitra RB: Fine needle aspiration cytology of thyroid gland and histopathological correlationRevisited. JIMA. 2002; 100(6): 49-54.

15. Ibrahim MM, Omar W, Elhofy A: Prospective study evaluating malignancy in solitary thyroid nodule. Egypt J Surg. 2019; 38(3): 411.

16. Huque SM, Ali MI, Huq M et al: Histopathological pattern of malignancy in solitary thyroid nodule, Bangladesh J Otorhinolaryngol. 2012; 18(1): 5-10.

17. Harshvardhan R, Jorwal V, Gupta S, Sharma V, Sehra R, Agarwal S: Assessment of Accuracy of Fine Needle Aspiration Cytology and Ultrasonography in Relation to Histopathology in Cases of Solitary Thyroid Nodule. Indian Journal of Otolaryngology and Head \& Neck Surgery. 2020; 1-8.

18. Basharat $R$, Bukhari $M H$, Saeed $S$, Hamid $T$ : Comparison of fine needle aspiration cytology and thyroid scan in solitary thyroid nodule. Pathology Research International. 2011; (1): 1-9.

19. Lakshmi YA, Reddy KVN: A clinicopathological evaluation of solitary nodule in thyroid; a retrospective observational hospital based study. Int Surg J. 2020; 7: 3951-3954.

20. Haider SA, Memon S, Laghari MS, et al: Efficacy of Fine Needle Aspiration and Cytology in Solitary Thyroid Nodule. Journal of Pharmaceutical Research International. 2021; 33(17): 1-6.

21. Williams NS, Christopher JK: O'Connell BPR. The Thyroid and Parathyroid Glands. Bailey and Love's Short Practice of Surgery. 2012; 51(26): 741-787.

22. Bhamre S., Chaudhari S: Clinical study of solitary nodule of thyroid at tertiary health centre. MVP J. Med. Sci. 2019; 6(1): 15-21.

23. Hassan $M Q$, Hasanat MA, Fariduddin $M$, et al: Fine needle aspiration cytological diagnosis of thyroid nodule with its clinical correlation. Bangabandhu Sheikh Mujib Medical University Journal. 2013; 6(2): 108-115. 
24. Sharma R, Verma N, Kaushal V, et al: Diagnostic accuracy of fine-needle aspiration cytology of thyroid gland lesions: A study of 200 cases in Himalayan belt. J Can Res Ther. 2017; 13: 451455.

25. Tarrar AM, Wahla MS, Ilyas S, etal. Solitary Thyroid Nodule; Frequency of Malignancy at Combined Military Hospital Rawalpindi, Professional Medical Journal. 2010; 17(4): 598-602.

26. Keshri SP: Clinico-Pathological Study of Solitary Thyroid Nodule with Special Reference to Fine Needle Aspiration Cytology, IJSR. 2017; 6(2): 789-794.

27. Cappelli C, Pirola I, Gandossi E, et al: Fine-needle aspiration cytology of thyroid nodule: does the needle matter? Southern Medical Journal. 2009; 102(5): 498-501.

28. Mihailescu DV, Schneider AB: Size, number, and distribution of thyroid nodules and the risk of malignancy in radiation-exposed patients who underwent surgery. The Journal of Clinical Endocrinology \& Metabolism. 2008; 93(6): 21882193.

29. Burkan Nasr, Burkan Nasr, Mohammed Qubati, et al. Diagnosis and surgical management of solitary thyroid nodule. Research Square. 2020; (1) 1-39.

30. Jaykar RD, Jadhav SC, Nirogi P: Study of clinical profile of solitary thyroid nodule and its management. International Journal of Surgery. 2021; 5(2): 207-210.

31. Cavallo A, Johnson DN, White MG, et al: Thyroid nodule size at ultrasound as a predictor of malignancy and final pathologic size. Thyroid. 2017; 27(5): 641-650.

32. Godazandeh G, Kashi Z, Zargarnataj S, et al: Evaluation the relationship between thyroid nodule size with malignancy and accuracy of fine needle aspiration biopsy. Acta Informatica Medica. 2016; 24 (5): 347-350.

33. Valderrabano $\mathrm{P}$, Khazai L, Thompson ZJ, et al: Association of tumor size with histologic and clinical outcomes among patients with cytologically indeterminate thyroid nodules. JAMA Otolaryngol Head Neck Surg. 2018; 144(9): 788-795.

34. Kwak J, Han K, Yoon J, et al: Thyroid imaging reporting and data system for US features of nodules: A step in establishing better stratification of cancer risk. Radiology. 2011; 260: 892-899.

35. Srinivas MN, Amogh VN, Gautam MS, et al: A prospective study to evaluate the reliability of thyroid imaging reporting and data system in differentiation between benign and malignant thyroid lesions. Journal of Clinical Imaging Science. 2016; 6: 5.

36. De D, Dutta S, Tarafdar S, et al: Comparison between sonographic features and fine needle aspiration cytology with histopathology in the diagnosis of solitary thyroid nodule. Indian $\boldsymbol{J}$ Endocr Metab. 2020; 24: 349-354.

37. Kaur K, Sonkhya N, Bapna AS, et al: A comparative study of fine needle aspiration cytology, ultrasonography and radionuclide scan in the management of solitary thyroid nodule: A prospective analysis of fifty cases, Ind. $\boldsymbol{J}$. Otolaryngol Head Neck Surg. 2002; 54(2): 96-101.

38. Sachin ID, Omprakash M, Amarendra P: Correlation of clinical, cytological, sonological diagnosis with histopathological diagnosis in cases of clinically diagnosed solitary thyroid nodule. Int Surg J. 2019; 6: 2849-2855.

39. Rajendran S, Prabu KRM: Clinico pathological aspects of solitary thyroid nodule: A hospital based prospective study. Int Surg J. 2018; 5: 1852-1855.

40. Prakash H Muddegowda. Panoramic ultrasound of the thyroid, Int. J. Med. Health Sci. 2012; 1(1): 19-23.

41. Susmitha MS, Veena S, Ramesh KB: Fine needle aspiration cytology of solitary thyroid nodule with histopathology correlation. Annals of Pathology and Laboratory Medicine. 2017; 4: 6.

42. Dantanarayana D.U., Sheriff M., Gallage G.R., et al: Role of fine-needle aspiration cytology \& ultrasound in the management of solitary thyroid nodule. Ceylon Journal of Otolaryngology. 2019; 8 (1): 27-35.

43. Iqbal J., Aziz O., Ahmad N., et al. Diagnostic accuracy of fine needle aspiration cytology in the diagnosis of malignant solitary thyroid nodule. Pak Armed Forces Med J. 2016; 66(4): 475-478.

44. Karim Md, Rosen N, Nikolay F, et al: A study on evaluation of solitary nodular thyroid lesions by FNAC and its histopathological correlation. Bangladesh Journal of Medical Science. 2019; 18: 789-795.

45. Bamanikar S, Soraisham P, Jadhav S, et al: Cytohistology and clinical correlation of thyroid gland lesions: A 3 year study in tertiary hospital. Cl Cancer Invest J. 2014; 3(1): 208-212.

46. Bukhari MH, Niazi S, Hanif G, Qureshi SS, Munir M, Hasan M, Naeem S: An updated audit of fine needle aspiration cytology procedure of solitary thyroid nodule. Diagn Cytopathol. 2008; 36(2): 104-112. 